\title{
Low Molecular Weight Organogelators Derived from Three-Fold Symmetric Tricarbamates
}

Xiaodong Hou, Jonathan Butz, Jiao Chen, Zijun D. Wang, Julia X. Zhao, Tiffany Shiu, and Qianli Rick Chu*

Department of Chemistry, University of North Dakota, Grand Forks, ND 58202, USA

KEYWORDS: Organogel, low molecular weight gelator, three-fold symmetry, carbamate, supramolecular atropisomer, hydrogen bond, LMOG, LMWG

ABSTRACT: A group of new low molecular weight organogelators based on three-fold symmetric tricarbamate were synthesized and characterized. The tricarbamates with long alkyl chains were able to gelate a wide range of polar and nonpolar organic solvents such as acetonitrile and cyclohexane, generally at concentrations lower than $20 \mathrm{~g} / \mathrm{L}$. The best organogel formation was obtained using a three-fold symmetric tricarbamate in $n$ dodecane, in which a sufficiently transparent gel was formed at the critical gelation concentration $1 \mathrm{~g} / \mathrm{L}$. Intermolecular hydrogen bonding by the tricarbamate in a nonpolar solvent benzene- $d_{6}$ was indicated by ${ }^{1} \mathrm{H}$ NMR spectra. Its UV absorption maximum was 11 $\mathrm{nm}$ higher in chloroform than in $n$-dodecane, and this red shift indicated increased conjugation between the benzene core and the carbamate substituents, which confirmed a change in conformation from nonpolar to polar. The self-assembling behavior of the tricarbamate in dilute solutions was investigated by TEM. Fiber-like networks were observed in a large range of solution concentrations. 


\section{INTRODUCTION}

Low Molecular Weight Organogelators (LMOGs) have been attracting attention not only for their potential applications ranging from oil spill remediation ${ }^{1}$ to art conservation, ${ }^{2}$ but also for their capacity to form a variety of interesting self-assemblies as fibers, sheets, tapes or strands that researchers do not fully understand. ${ }^{3}$ The gelation process of LMOGs is thermo-reversible: small molecules self-assemble into three-dimensional supramolecular networks that entrap solvents by surface tension. Models for supramolecular structures of the aggregates have been proposed, but the true nature of the aggregation phenomenon is still under investigation. ${ }^{4,5}$ Meanwhile, despite the fact that many efforts have been made to fully understand the mechanism and establish guidelines for the rational design of organogelators, many novel organogelators have been discovered by serendipity rather than design. ${ }^{3 c, 6}$

In this communication, we report a new group of LMOGs based on three-fold symmetric tricarbamates that were found during our study of a series of supramolecular atropisomers $^{5 \mathrm{a}, 7}$ and symmetric monomers with multiple reactive centers. ${ }^{8}$ In contrast to the numerous reports on LMOGs based on other $\mathrm{N}$ - and O-containing compound counterparts such as amide, amino, and urea, only a limited number of reports have studied LMOGs based mainly on intermolecular H-bonding of carbamate. ${ }^{9}$ There are a number of advantages of this new tricarbamate system: Their syntheses were accomplished using readily available and inexpensive benzene-1,3,5-tricarbonyl trichloride, sodium azide, and alcohols in good yields. Three-fold symmetry allows installation of a corresponding side- 
chain group to each carbonyl group at the same time, ${ }^{10}$ with long alkyl group-containing chains generally improve solubility of the resulting compound. The tricarbamates showed good thermal stability due to the presence of a large conjugated system. Moreover, considering the multitude of alcohols that are commercially available or easy to synthesize, there is an opportunity to further tweak the properties of the LMOGs of three-fold symmetric tricarbamates according to the future academic study or per industrial production requirements.

\section{RESULT AND DISCUSSION}

Nine three-fold symmetric tricarbamates were readily synthesized in excellent yield as shown in Scheme 1 by reacting the corresponding primary alcohol with 1,3,5triisocyanatobenzene, ${ }^{11}$ derived from 1,3,5-benzenetricarbonyl chloride in a two-step, onepot reaction. After purification by column chromatography, tricarbamates were characterized by ${ }^{1} \mathrm{H}$ NMR, ${ }^{13} \mathrm{C}$ NMR, FT-IR, and mass spectroscopy. The nine symmetric tricarbamates are labeled as $\mathbf{C}-\boldsymbol{n}(\mathbf{C}-\mathbf{1} \sim \mathbf{C - 8}$ and $\mathbf{C - 1 2})$, where the $\boldsymbol{n}$ is the carbon number of its alkyl chain. Details of the synthetic procedure and characterization are included in the supporting information. The tricarbamates were very stable under ambient conditions and did not decompose after one-year storage. 


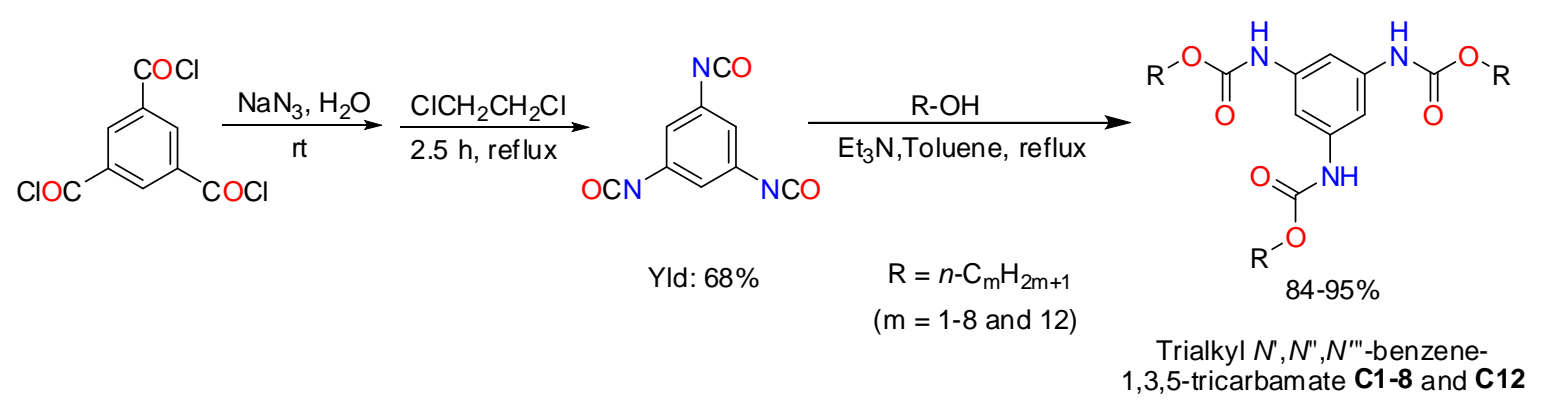

Scheme 1. Synthesis of the tricarbamates

In contrast to the poor solubility of linear long-chain carbamates in most solvents, ${ }^{9 \mathrm{~d}}$ three-fold symmetric tricarbamates are generally soluble in common organic solvents. The increased solubility is perhaps because it is difficult for the three-armed carbamates to quickly form repeatable close packing in the solid state, especially for those with long alkyl chains. ${ }^{5}$ Their high solubility makes it easy to test the gelation properties. The gelation capability of this group of tricarbamates was tested with different solvents and shown in Table 1 . In a typical concentration of $20 \mathrm{~g} / \mathrm{L}\left(2.6 \times 10^{-2} \mathrm{M}\right)$ in $n$-dodecane, the tricarbamates such as $\mathbf{C - 1}$ and $\mathbf{C - 2}$ with short alkyl side chains had relatively low solubility and formed crystalline precipitate, and crystals grew on the sidewall of the vial upon slow evaporation of the solvent. With the increase of the alkyl side chain length, the tricarbamates solubility in $n$-dodecane increased accordingly and did not precipitate rapidly. The partial organogels of $\mathbf{C - 5}$ and $\mathbf{C}-\mathbf{6}$ showed high viscosity, but could not pass the vial inversion test. However, as the alkyl chain length was further increased, the solid gels formed quickly and held their position during vial inversion. As shown in Figure 1, while C-7 organogel lost about $5 \%$ of $n$-dodecane solvent during the vial inversion test, $\mathbf{C}$ 8 and $\mathbf{C - 1 2}$ organogel were able to completely immobilize the solvent. 
Table 1. Gelation capability of $\mathbf{C - 1} \sim \mathbf{C - 1 2}$ in $n$-dodecane (20 g/L)

\begin{tabular}{ccccccccc}
\hline C-1 & C-2 & C-3 & C-4 & C-5 & C-6 & C-7 & C-8 & C-12 \\
\hline $\begin{array}{c}\text { Crystalline } \\
\text { precipitate }\end{array}$ & $\begin{array}{c}\text { Sparingly } \\
\text { soluble }\end{array}$ & Suspension & Suspension & $\begin{array}{c}\text { Partial } \\
\text { gel }\end{array}$ & $\begin{array}{c}\text { Partial } \\
\text { gel }\end{array}$ & $\begin{array}{c}\text { Solid } \\
\text { gel }\end{array}$ & $\begin{array}{c}\text { Solid } \\
\text { gel }\end{array}$ & $\begin{array}{c}\text { Solid } \\
\text { gel }\end{array}$ \\
\hline
\end{tabular}

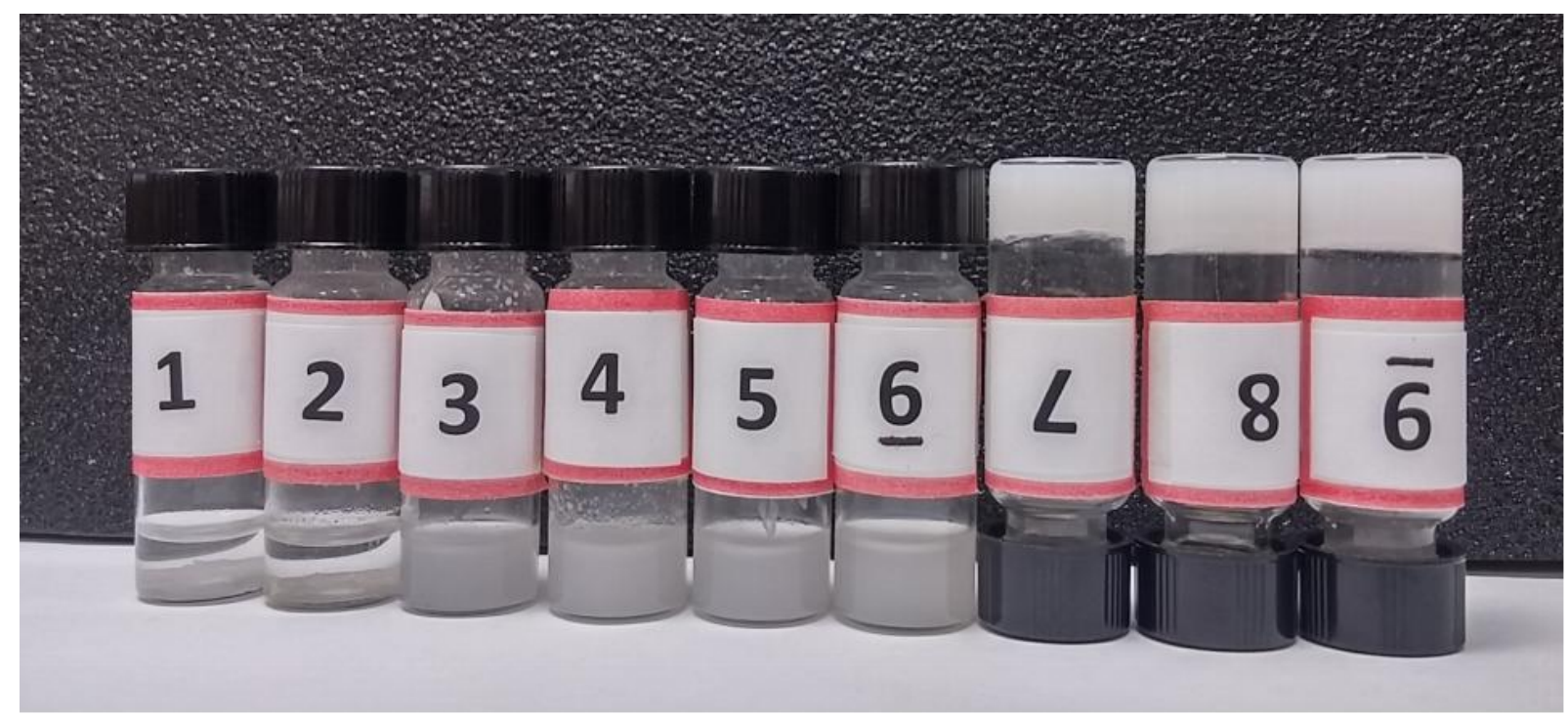

Figure 1. Sample 1-8 corresponds to tricarbamate $\mathbf{C - 1} \sim \mathbf{C - 8}$ and sample 9 is $\mathbf{C - 1 2}$ at 20 $\mathrm{g} / \mathrm{L}\left(2.6 \times 10^{-2} \mathrm{M}\right)$ in $n$-dodecane.

Tricarbamate $\mathbf{C - 1 2}$ was chosen to further study its gelation capability. It was found that C-12 was able to form organogels with a wide range of solvents from polar solvents, like acetonitrile, to nonpolar solvents, such as toluene, generally at a critical gel concentration (CGC) around $20 \mathrm{~g} / \mathrm{L}$ in these solvents. The results are summarized in Table 2. Decalin and methylcyclohexane could be gelled at concentration of $10 \mathrm{~g} / \mathrm{L}$. The best gelation result of tricarbamate $\mathbf{C - 1 2}$ was observed in a nonpolar solvent, $n$-dodecane, in which the critical gelation concentration of $1 \mathrm{~g} / \mathrm{L}\left(1.3 \times 10^{-3} \mathrm{M}\right)$ was remarkably low. To the best of our 
knowledge, the above value of $1 \mathrm{~g} / \mathrm{L}$ is among the best gelation capabilities of all reported organogelators. A further interesting feature is that the $1 \mathrm{~g} / \mathrm{L}$ of tricarbamate $\mathbf{C - 1 2}$ gel in $n$ dodecane is nearly transparent (Figure 2), which expands its potential applications.

Table 2. Critical Gel Concentration (CGC) of tricarbamate C-12 for a Variety of Solvents

\begin{tabular}{cccc}
\hline Solvents & CGC $^{a}$ & Solvents & CGC \\
\hline$n$-dodecane & $1^{a}$ & $n$-Hexane & 20 \\
$\begin{array}{c}\text { Decalin } \\
\text { Methyl } \\
\text { cyclohexane }\end{array}$ & 10 & 1-Dodecanol & 20 \\
$\begin{array}{c}\text { Toluene } \\
\text { Cyclohexane }\end{array}$ & 10 & Acetonitrile & 20 \\
\hline
\end{tabular}

${ }^{a}$ the critical gelation concentration is showed as $\mathrm{g} / \mathrm{L}$.

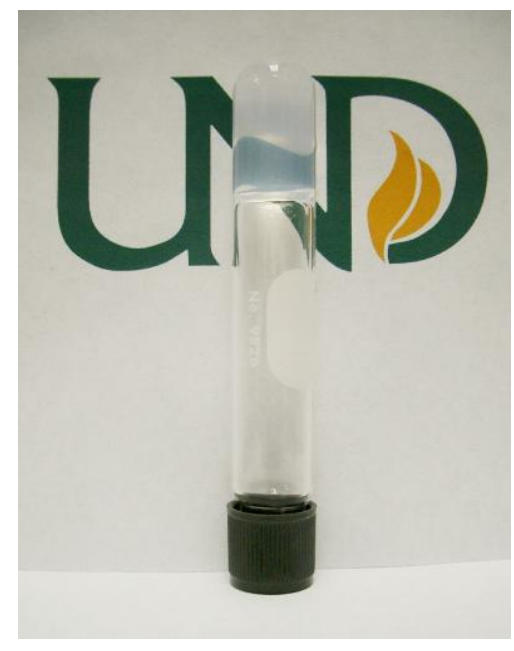

Figure 2. Transparent gel of the tricarbamate $\mathbf{C - 1 2}$ in $n$-dodecane $\left(1 \mathrm{~g} / \mathrm{L}\right.$, or $\left.1.3 \times 10^{-3} \mathrm{M}\right)$ 
The formation of intermolecular hydrogen bonding was indicated by ${ }^{1} \mathrm{H}$ NMR spectra of tricarbamate $\mathbf{C - 1 2}$ in benzene- $d_{6}$. As shown in Figure 3, as the concentration of the solution decreases from $100 \mathrm{mM}$ to $1.5 \mathrm{mM}$, the chemical shift of the active proton of the carbamate group is gradually moved upfield ${ }^{12}$ The substantial upfield-shifting of the carbamate proton signal upon dilution is consistent with the presence of intermolecular hydrogen bonding interaction in solution. Because the formation of strong intramolecular hydrogen bonding is impossible for compound C-12 due to the location and distance between the three carbamate groups around the aromatic core, the concentration dependence of the N-H chemical shift can be explained by intermolecular hydrogen bonding. With the change of the concentration, the geometry and composition of the hydrogen bonded aggregates change accordingly, so the chemical environment change of hydrogen bonded N-H within the aggregates causes the upfield-shifting of its ${ }^{1} \mathrm{H}$ NMR signal. If the C-12 molecules had presented as individual molecules in benzene- $d_{6}$, the N-H would have been able to freely find its most comfortable conformation despite its concentration and there would have not been significant change upon dilution. 


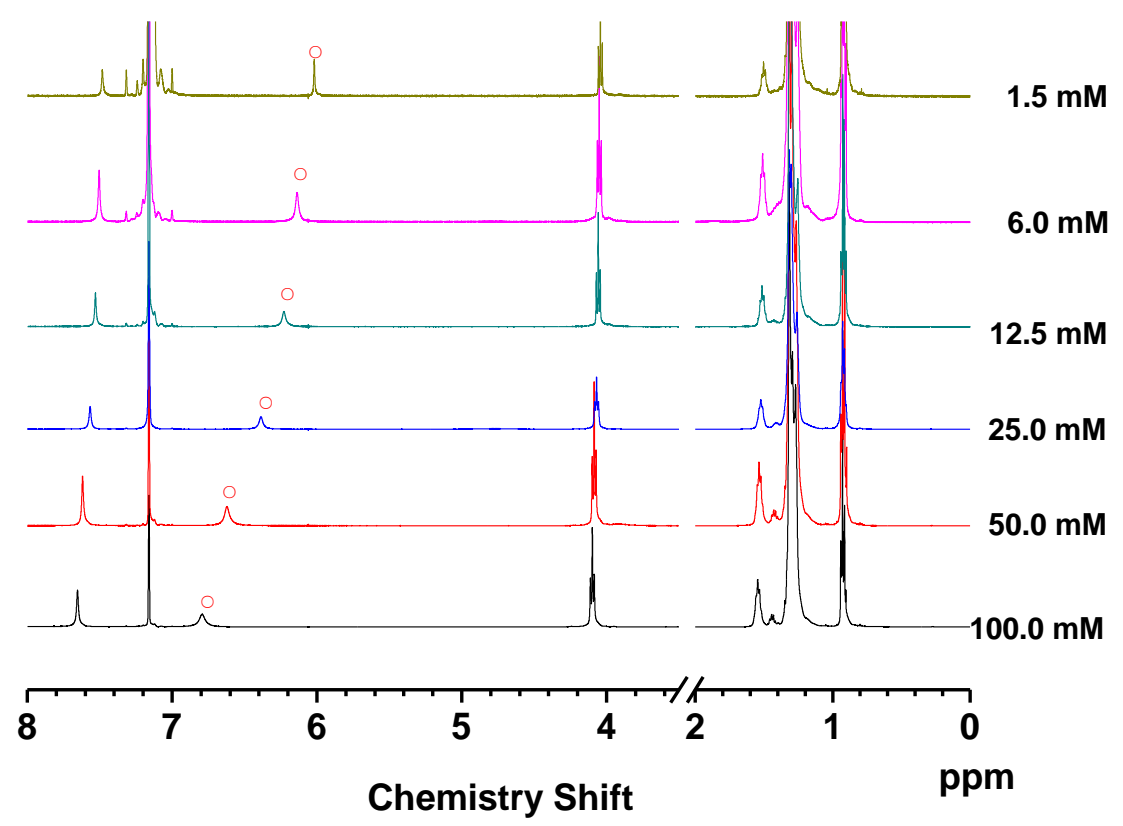

Figure 3. ${ }^{1} \mathrm{H}$ NMR spectra of tricarbamate $\mathbf{C}-12$ at various concentrations of benzene- $d_{6}$. Chemical shift of the $\mathrm{N}-\mathrm{H}$ gradually moves upfield with decreasing solution concentrations. The NMR solutions must remain below the gelation point or else high resolution spectra cannot be obtained.

As presented in Figure 4, the absorption maximum was at $234 \mathrm{~nm}$ in $n$-dodecane. In a more polar solvent, chloroform, it was shifted to $245 \mathrm{~nm}$, which was $11 \mathrm{~nm}$ higher than in $n$-dodecane. Similar shifts of absorbance peak have been observed in benzene-1,3,5tricarboxamides systems. ${ }^{13}$ The potential of forming six or more hydrogen bonds makes it unfavorable for the tricarbamate $\mathbf{C - 1 2}$ or similar compounds to present as individual molecules in chloroform. Thus, the red shift might indicate an increase in conjugation between the benzene unit and the carbamate substituent due to conformational change in the hydrogen bonded aggregates from nonpolar $n$-dodecane to polar chloroform solvent. 
Figure 4. UV-Vis spectra of tricarbamate $\mathbf{C}-12\left(10^{-5} \mathrm{M}\right)$ in polar and nonpolar solvents at room temperature. Both curves have been normalized for convenience of comparison.

To explore the supramolecular structure of the $\mathbf{C - 1 2}$ organogel, powder X-ray Powder Diffraction (XRD) analysis was performed. There was only one small peak around 7 degrees and a broad peak around 20 degrees in the powder XRD pattern (Figure S8 in the ESI), so the tricarbamate $\mathbf{C - 1 2}$ did not form a well-defined crystalline aggregate as its tricarbamate and triamide analogues. ${ }^{5 a, 7}$ To explore the microscopic structure of the transparent organogel, electron microscopic analysis was performed. Figure 5a shows a Transmission Electron Microscopy (TEM) image of the $n$-dodecane gel of tricarbamate $\mathbf{C}$ 12 at a concentration of $1 \mathrm{~g} / \mathrm{L}\left(1.3 \times 10^{-3} \mathrm{M}\right)$. From the TEM images, entangled fiber-like structures were observed with diameters ranging from about twenty to several hundred 
nanometers. The elongated self-assemblies reach dozens of micrometers in length, which is corresponding to thousands of tricarbamate molecules assembled together. During the testing of the critical gelation concentration of tricarbamate $\mathbf{C - 1 2}$ in $n$-dodecane, it was found $n$-dodecane could still be partially congealed when the concentration was diluted to $5 \times 10^{-4} \mathrm{M}$. Three concentrations of solution ranging from $10^{-4}$ to $10^{-5} \mathrm{M}$ were cooled down from near the boiling point of $n$-dodecane, dried in the air, and photographed using TEM. As shown in the Figure $5(b-d)$, fiber-like structures were also formed with samples from the all three concentrations of solutions. The shape and size of the aggregates were similar to those observed with the $1 \mathrm{~g} / \mathrm{L}\left(1.3 \times 10^{-3} \mathrm{M}\right.$, Figure $\left.5 \mathrm{a}\right)$ gel further showing that the gelation process is general and reliable. 

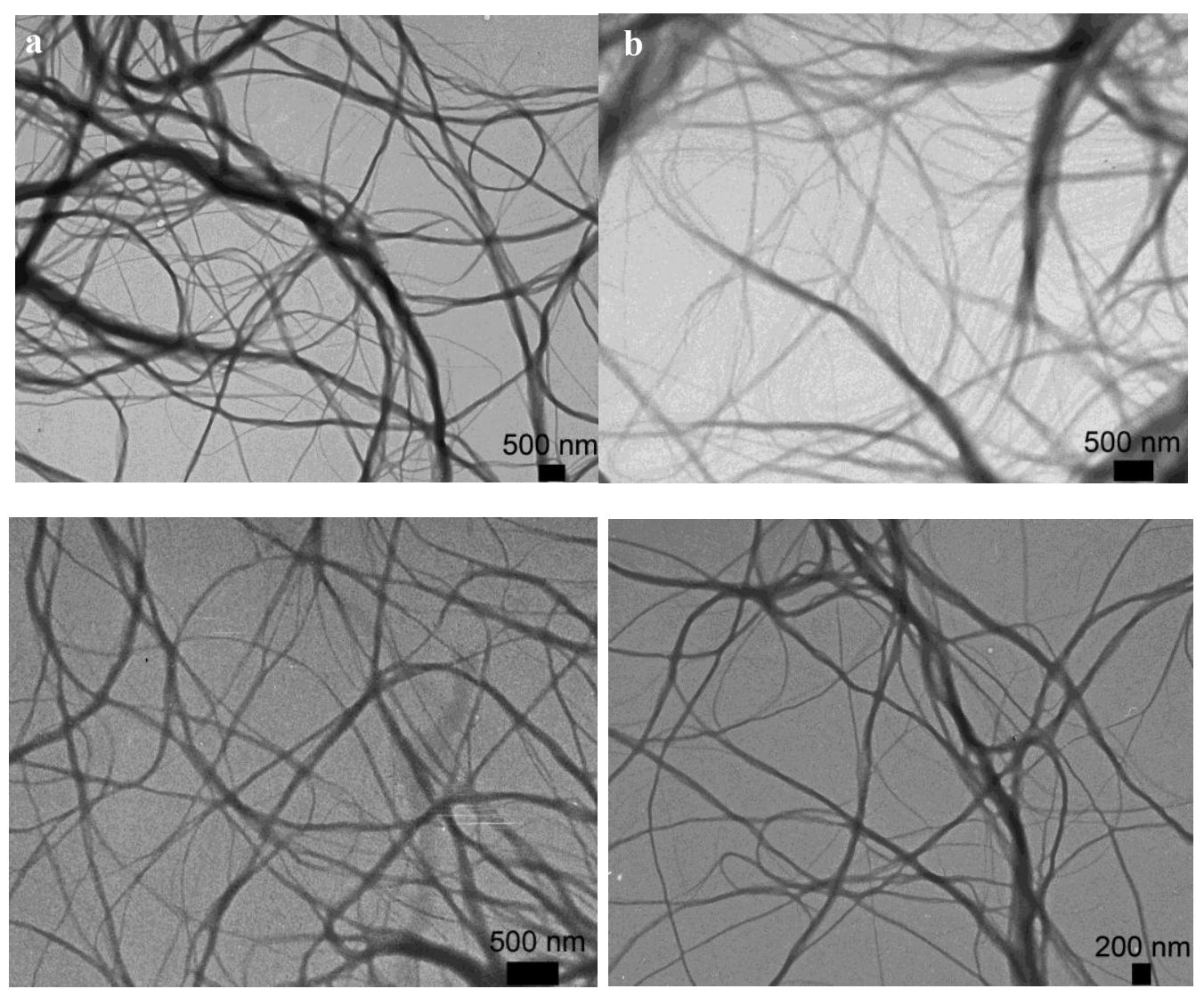

Figure 5. TEM images of nanofibers formed by tricarbamate $\mathbf{C - 1 2}$ in $n$-dodecane: (a) gel at $1 \mathrm{~g} / \mathrm{L}\left(1.3 \times 10^{-3} \mathrm{M}\right)$, (b) solution at $10^{-4} \mathrm{M}$, (c) solution at $5 \times 10^{-4} \mathrm{M}$, and (d) solution at $5 \times 10^{-5} \mathrm{M}$. The solutions were prepared by heating close to the boiling temperature of $n$ dodecane and then cooled down in air.

In summary, a new family of LMOGs based on the three-fold symmetric tricarbamate were synthesized, characterized, and studied. The tricarbamates with long alkyl chains were able to gelate a variety of organic solvents and showed remarkable gelation ability in nonpolar solvents. ${ }^{6 a}$ Fiber-like networks were observed under TEM in a wide range of solution concentrations. The readily available starting materials, ease of synthesis, good solubility and stability of the three-fold symmetric tricarbamates make them attractive 
members of LMOGs. ${ }^{10}$ The potential applications of the organogels and their derivatives include serving as responsive soft materials or being used as templates and stabilizers in the synthesis of polymeric, inorganic, and hybrid nanomaterials. ${ }^{14}$

\section{ASSOCIATED CONTENT}

Supporting Information. Experimental procedure, full characterizations and spectra can be found in the supporting information. This material is available free of charge via the Internet at http://www.sciencedirect.com/science/journal/00404039

\section{AUTHOR INFORMATION}

\section{Corresponding Author}

E-mail: chu@chem.und.edu (Q. R. Chu); Fax: 701-777-2331; Tel: 701-777-3941

\section{ACKNOWLEDGEMENT}

This research is supported by the National Science Foundation (NSF, Grant \# EPS0814442) and the Doctoral New Investigator grants of the American Chemical Society Petroleum Research Fund (PRF 52705-DNI7). The authors acknowledge Dr. Angel Ugrinov at North Dakota State University (NDSU) for HRMS assistance.

\section{REFERENCES}


1 Ohsedo, Y. Polym. Adv. Technol. 2016, 27, 704-711.

2 Carretti, E.; Dei, L.; Weiss, R. G. Soft Matter 2005, 1, 17-22.

3 (a) Samai, S.; Dey, J.; Biradha, K. Soft Matter 2011, 7, 2121-2126; (b) Ishi-i, T.; Shinkai, S. Top. Curr. Chem. 2005, 258, 119-160; (c) de Loos, M.; Feringa, B. L.; van Esch, J. H. Eur. J. Org. Chem. 2005, 3615-3631; (d) Gronwald, O.; Snip, E.; Shinkai, S. Curr. Opin. Colloid Interface Sci. 2002, 7, 148-156; (e) George, M.; Weiss, R. G. Acc. Chem. Res. 2006, 39, 489-497.

4 https://en.wikipedia.org/wiki/J-aggregate (Accessed in Oct. 2016)

5 (a) Hou, X.; Schober, M.; Chu, Q. Cryst. Growth Des. 2012, 12, 5159-5163; (b) Zehe, C.; Schmidt, M.; Siegel, R.; Kreger, K.; Daebel, V.; Ganzleben, S.; Schmidt, H.-W.; Senker, J. CrystEngComm 2014, 16, 9273-9283; (c) Markvoort, A. J.; ten Eikelder, H. M. M.; Hilbers, P. A. J.; de Greef, T. F. A.; Meijer, E. W. Nat. Commun. 2011, 2, 509; (d) Bejagam, K. K.; Fiorin, G.; Klein, M. L.; Balasubramanian, S. J. Phys. Chem. A 2014, 118, 5218-5228; (e) Cantekin, S.; Balkenende, D. W. R.; Smulders, M. M. J.; Palmans, A. R. A.; Meijer, E. W. Nat. Chem. 2011, 3, 42-46; (f) Leenders, C. M. A.; Jansen, G.; Frissen, M. M. M.; Lafleur, R. P. M.; Voets, I. K.; Palmans, A. R. A.; Meijer, E. W. Chem. Eur. J. 2016, 22, 4608-4615.

6 (a) Abdallah, D. J.; Weiss, R. G. Adv. Mater. 2000, 12, 1237-1247; (b) Menger, F. M.; Caran, K. L. J. Am. Chem. Soc. 2000, 122, 11679-11691; (c) Suzuki, M.; Nakajima, Y.; Yumoto, M.; Kimura, M.; Shirai, H.; Hanabusa, K. Langmuir 2003, 19, 8622-8624.

7 (a) Wang, Z.; Lee, J.; Oian, C.; Hou, X.; Wang, Z.; Ugrinov, A.; Singh, R. K.; Wysocki, E.; Chu, Q. R. CrystEngComm 2014, 16, 7176-7179; (b) Hou, X.; Wang, Z.; Overby, M.; Ugrinov, A.; Oian, C.; Singh, R.; Chu, Q. R. Chem. Commun. 2014, 50, 5209-5211; (c) Singh, R. K.; Hou, X.; Overby, M.; Schober, M.; Chu, Q. CrystEngComm. 2012, 14, 61326135 .

8 (a) Randazzo, K.; Wang, Z.; Wang, Z. D.; Butz, J.; Chu, Q. R. ACS Sustain. Chem. Eng. 2016, 4, 5053-5059; (b) Wang, Z.; Randazzo, K.; Hou, X.; Simpson, J.; Struppe, J.; Ugrinov, A.; Kastern, B.; Wysocki, E.; Chu, Q. R. Macromolecules 2015, 48, 2894-2900; (c) Wang, Z.; Kastern, B.; Randazzo, K.; Ugrinov, A.; Butz, J.; Seals, D. W.; Sibi, M. P.; Chu, Q. R. Green Chem. 2015, 17, 4720-4724; (d) Hou, X.; Wang, Z.; Lee, J.; Wysocki, E.; Oian, C.; Schlak, J.; Chu, Q. R. Chem. Commun. 2014, 50, 1218-1220; (e) Singh, R.; Schober, M.; Hou, X.; Seay, A.; Chu, Q. Tetrahedron Lett. 2012, 53, 173-175.

9 (a) Huang, X.; Terech, P.; Raghavan, S. R.; Weiss, R. G. J. Am. Chem. Soc. 2005, 127, 4336-4344; (b) Lu, L.; Cocker, T. M.; Bachman, R. E.; Weiss, R. G. Langmuir 2000, 16, 20-34; (c) Hanabusa, K.; Okui, K.; Karaki, K.; Koyama, T.; Shirai, H. J. Chem. Soc., Chem. Commun. 1992, 1371-1373; (d) Moniruzzaman, M.; Sundararajan, P. R. Langmuir 2005, 21, 3802-3807; (e) Cicchi, S.; Ghini, G.; Lascialfari, L.; Brandi, A.; Betti, F.; Berti, D.; Ferrati, S.; Baglioni, P. Chem. Commun. 2007, 1424-1426.

10 (a) Gibson, S. E.; Castaldi, M. P. Angew. Chem. Int. Ed. 2006, 45, 4718-4720; (b) Foster, J. S.; Żurek, J. M.; Almeida, N. M. S.; Hendriksen, W. E.; le Sage, V. A. A.; Lakshminarayanan, V.; Thompson, A. L.; Banerjee, R.; Eelkema, R.; Mulvana, H.; Paterson, M. J.; van Esch, J. H.; Lloyd, G. O. J. Am. Chem. Soc. 2015, 137, 14236-14239.

11 Davis, M. C. Synth. Commun. 2007, 37, 3519-3528. 
12 (a) Invernizzi, C.; Dalvit, C.; Stoeckli-Evans, H.; Neier, R. Eur. J. Org. Chem. 2015, 2015, 5115-5127; (b) Qu, S.; Li, F.; Wang, H.; Bai, B.; Xu, C.; Zhao, L.; Long, B.; Li, M. Chem. Mater. 2007, 19, 4839-4846; (c) Black, D. S. C.; Craig, D. C.; McConnell, D. B. J. Am. Chem. Soc. 1996, 118, 8148-8149.

13 (a) Smulders, M. M. J.; Schenning, A. P. H. J.; Meijer, E. W. J. Am. Chem. Soc. 2008, 130, 606-611; (b) van Hameren, R.; van Buul, A. M.; Castriciano, M. A.; Villari, V.; Micali, N.; Schoen, P.; Speller, S.; Scolaro, L. M.; Rowan, A. E.; Elemans, J. A. A. W.; Nolte, R. J. M. Nano Lett. 2008, 8, 253-259; (c) Palmans, A. R. A.; Vekemans, J. A. J. M.; Havinga, E. E.; Meijer, E. W. Angew. Chem., Int. Ed. 1997, 36, 2648-2651; (d) Stals, P. J. M.; Smulders, M. M. J.; Martin-Rapun, R.; Palmans, A. R. A.; Meijer, E. W. Chem. Eur. J. 2009, 15, 2071-2080; (e) Stals, P. J. M.; Everts, J. C.; de Bruijn, R.; Filot, I. A. W.; Smulders, M. M. J.; Martin-Rapun, R.; Pidko, E. A.; de Greef, T. F. A.; Palmans, A. R. A.; Meijer, E. W. Chem. Eur. J. 2010, 16, 810-821, S810/811-S810/816.

14 (a) Smith, D. K. Tetrahedron 2007, 63, 7283-7284; (b) de Feijter, I.; Albertazzi, L.; Palmans, A. R. A.; Voets, I. K. Langmuir 2015, 31, 57-64; (c) van Bommel, K. J. C.; van der Pol, C.; Muizebelt, I.; Friggeri, A.; Heeres, A.; Meetsma, A.; Feringa, B. L.; van Esch, J. Angew. Chem. Int. Ed. 2004, 43, 1663-1667; (d) Tan, G.; Singh, M.; He, J.; John, V. T.; McPherson, G. L. Langmuir 2005, 21, 9322-9326; (e) Chen, J.; Wu, X.; Hou, X.; Su, X.; Chu, Q.; Fahruddin, N.; Zhao, J. X. ACS Appl. Mater. Interfaces 2014, 6, 21921-21930; (f) Llusar, M.; Sanchez, C. Chem. Mater. 2008, 20, 782-820. 


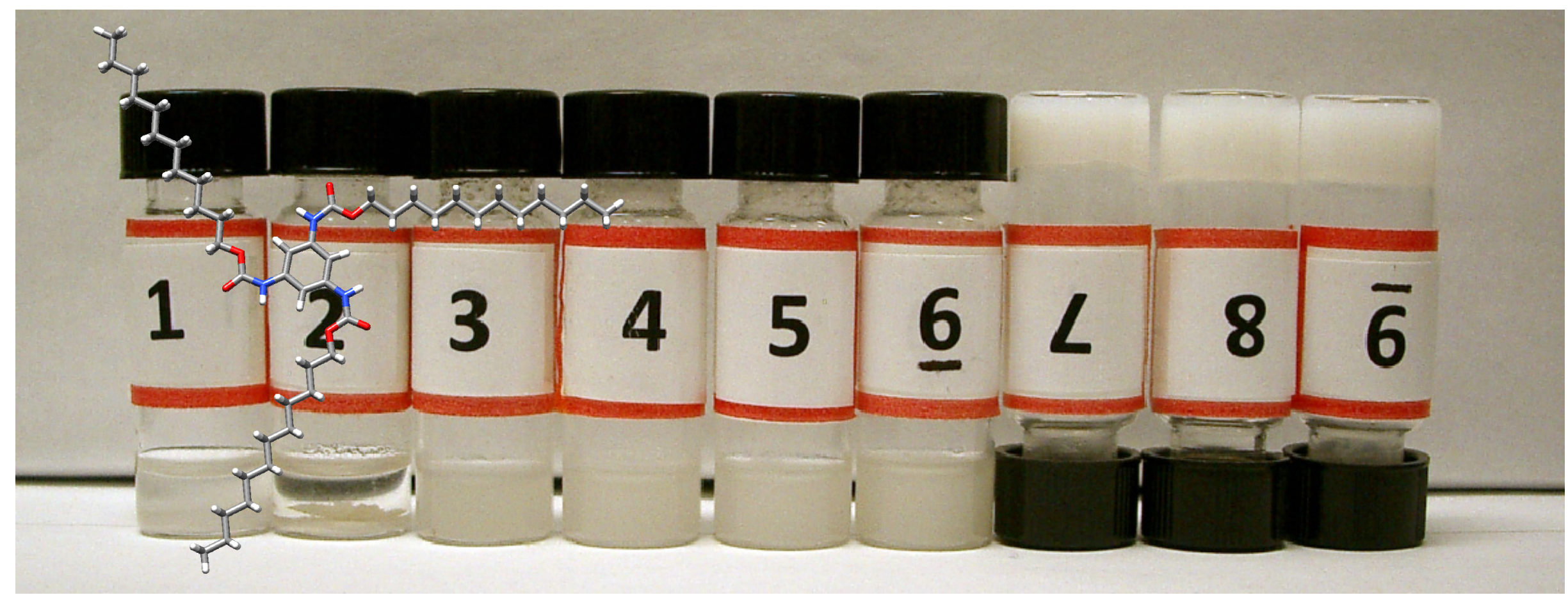

